\title{
Interstitial Fibrosis Assessment
}

National Cancer Institute

\section{Source}

National Cancer Institute. Interstitial Fibrosis Assessment. NCI Thesaurus. Code C135468.

An evaluation of the presence or degree of interstitial fibrosis present in a sample. 